\title{
Micro-analyses of dust particles generated in the JET tokamak with the ITER-Like Wall
}

\author{
Stjepko Fazinicí ${ }^{1 *}$, Iva Božičević-Mihalić ${ }^{1 *}$, Georgios Provatas ${ }^{1}$, Tonči Tadić ${ }^{1}$, Marek \\ Rubel $^{2}$, Elżbieta Fortuna-Zaleśna ${ }^{3}$, Anna Widdowson ${ }^{4}$ and JET Contributors ${ }^{5}$ \\ EUROfusion Consortium, JET, Culham Science Centre, Abingdon, Oxfordshire OX14 3DB, United \\ Kingdom of Great Britain and Northern Ireland \\ ${ }^{1}$ Division of Experimental Physics, Ruđer Bošković Institute, Zagreb, Croatia \\ ${ }^{2}$ Department of Fusion Plasma Physics, KTH Royal Institute of Technology, Stockholm, Sweden \\ ${ }^{3}$ Faculty of Materials Science and Technology, Warsaw University of Technology, Warsaw, Poland \\ ${ }^{4}$ Culham Centre for Fusion Energy, Culham Science Centre, Abingdon, OX14 3DB, UK \\ ${ }^{5}$ See the author list in Joffrin E et al., Overview of the JET preparation for deuterium-tritium operation \\ with the ITER like-wall, 2019 Nuclear Fusion 59112021 \\ *Coresponding authors e-mails: stjepko.fazinic@irb.hr, ibozicev@irb.hr
}

Received xxxxxx

Accepted for publication $\mathrm{xxxxxx}$

Published xxxxxx

\begin{abstract}
Dust generated in JET with the ITER-Like Wall (ILW) was collected from the divertor by vacuum cleaning and examined with ion and electron beam methods. From totally $1 \mathrm{~g}$ retrieved after the third ILW campaign (2015-2016) a number of specimens were prepared using sticky (adhesive) carbon tabs. The aim was to determine the distribution and amounts of constituents: from deuterium (D) to $\mathrm{W}$ with particular emphasis on the concentration ratio of D to other species. Two classes of particles containing deuterium were identified: (i) rich in $\mathrm{Be}$ and (ii) low-Z matrix without $\mathrm{Be}$, that show large $\mathrm{C}$ concentrations with some $\mathrm{O}$ contribution and minor contributions from heavier elements. The D content in Be-based particles has been at the level not exceeding $\approx 2$ at $\%$, whereas in the C-rich particles, both in small $(10-100 \mu \mathrm{m})$ and large conglomerates $(>100 \mu \mathrm{m})$, the D contribution at the level of about 15 to 20 at \% has been detected. W-rich particles are often accompanied by $\mathrm{Ni}, \mathrm{Cr}$ and Fe and occasionally with Mo. The results clearly indicate that fuel retention in the ILW dust is predominantly associated with residual $\mathrm{C}$, approximately 10-20 times greater retention was found in C-rich objects than in metal-based particles.
\end{abstract}

Keywords: JET tokamak, Dust, Ion beam analysis, Deuterium, Beryllium, Tungsten

\section{Introduction}

Wall components in controlled fusion devices undergo modification by a range of plasma-wall interaction (PWI) processes including material erosion and re-deposition. Some eroded material is converted into dust particles of the diverse composition and size. Dust generation is a serious issue for ITER [1]. In dust studies one needs to assess the amount and type of particles and the fuel content. For that reason a detailed research has been carried out in existing tokamaks with particular emphasis on dust generation in machines with metallic plasma-facing components such as ASDEX Upgrade with tungsten-coated wall tiles [2] and JET operated with the ITER-Like Wall (JET-ILW), i.e. material configuration that will be used in ITER: beryllium limiters in the main chamber and tungsten in the divertor $[3,4]$. All results obtained until now have consistently shown small amounts of loose dust formed in JET-ILW. About $1 \mathrm{~g}$ retrieved from the divertor after each of the three experimental campaigns comprising 
$19-23$ h of plasma operation [5-9], i.e. approximately 150 times less than after JET operation with carbon walls [10]. Particles collected from JET-ILW consist of Be, W, Inconel components from the vacuum vessel wall $(\mathrm{Ni}, \mathrm{Cr}, \mathrm{Fe})$, carbon from tungsten-coated divertor tiles made of carbon fibre composites (W-CFC) and other materials containing $\mathrm{Cu}$, Mo and other elements (B, Mg, Al, Si) together with $\mathrm{N}$ (originating from $\mathrm{N}_{2}$ puffing for edge cooling), $\mathrm{H}$ isotopes and $\mathrm{O}$. The latter comes as plasma impurity and due to the exposure of samples to air.

All these species (elements and respective isotopes) can be detected using a set of Ion Beam Analysis (IBA) techniques. Their usefulness in studies of plasma-facing components (PFC) in general [11] and for specific analysis of micro-particles with micro-beams focused to several $\mu \mathrm{m}$ [12] have been recently emphasized.

The composition and internal structure of the dust collected on carbon stickers directly from various regions of the JET divertor were studied after venting JET-ILW during its first shutdown [6] and after the second JET experimental campaign with the ILW (2013-14) [7, 8, 12]. Direct sampling from the upper region of the inner divertor, i.e. the most critical area from a deposition point of view, showed the presence of two types of Be particles of considerable importance for ITER: flakes of co-deposited layers and small droplets [7]. Two major particle classes of importance to ITER were identified: (i) mixed deposits rich in Be and (ii) metal droplets $(\mathrm{Be}, \mathrm{W}$, and $\mathrm{Ni}$ ) created in melting events of the wall materials [8]. In terms of elemental concentrations, two types of dust particles were found [12]: (i) larger Be-rich particles with Be content above 90 at $\%$ with a D presence of up to 3.4 at $\%$ and containing also small amounts of $\mathrm{Ni}, \mathrm{Cr}$, $\mathrm{W}, \mathrm{Fe}, \mathrm{Cu}, \mathrm{Ti}$; (ii) small particles rich in $\mathrm{Al}$ and/or $\mathrm{Si}$ that were in some cases accompanied by other elements, such as $\mathrm{Fe}, \mathrm{Cu}, \mathrm{Ti}, \mathrm{W}, \mathrm{Mo}$.

The previous study was focused on particles in the form of co-deposits sampled locally with a sticky carbon tab directly from the High Field Gap Closure tile (top of the inner divertor) [12]. This work is focused on the examination of dust retrieved by vacuum cleaning from 22 divertor modules (out of 24); the two remaining modules with installed erosion-deposition diagnostics were removed from JET intact for ex-situ studies of tiles and probes. A set of complementary electron and ion beam methods has been used with the aim to determine the composition of mixed material and to assess fuel retention in various types of particles.

\section{Experimental}

\subsection{Samples}

The study was carried out for particles retrieved from the divertor using a cyclone-type vacuum cleaner after the third
ILW campaign (ILW-3) in 2015-2016. Vacuuming was performed separately in the inner and in the outer divertor. Such procedure is considered to be the best method to assess the total amount of loose matter in the machine. As detailed in [9], there are disadvantages related to mixing of particles from various locations and to a risk of material disintegration in the cyclone equipment. It is not possible to directly associate dust morphology with the exact place of its origin and it is also rather difficult to find proper objects for detailed studies. In addition, exposure to air may influence the chemical composition of particles: oxidation, water vapour adsorption and the $\mathrm{D}-\mathrm{H}$ isotope exchange. Unfortunately, quantitative assessment of the impact of such processes on the $\mathrm{D}$ and $\mathrm{O}$ contents is not possible taking into account unavoidable air exposure of all types of materials (PFC, probes, dust) retrieved from fusion devices.

The dust collected in a pot of the vacuum cleaner was then transferred to a Petri dish to allow for sampling of two fractions: from the pot and from the dish. This was done to check whether decanting from the pot was not limited only to relatively bigger (heavier) particles. Sticky carbon tabs pressed against the walls of the pot and dish were used to immobilize particles and facilitate IBA and microscopy of four samples, as detailed in Table 1.

Table 1. Dust samples and their origin.

\begin{tabular}{cl}
\hline Sample & \multicolumn{1}{c}{ Origin } \\
\hline 86 & Outer divertor, sampled from vacuum pot \\
& interior \\
X1 & Outer divertor, sampled from Petri dish \\
87 & Inner divertor, sampled from vacuum pot \\
& interior \\
X3 & Inner divertor, sampled from Petri dish \\
\hline
\end{tabular}

\subsection{Measurements and data analysis}

2.2.1 Electron microscopy. Studies conducted at the Warsaw University of Technology (WUT) comprised highresolution scanning electron microscopy (SEM) and energy dispersive X-ray spectroscopy (EDS) using Hitachi SU-70 FE-SEM. To ensure proper identification of beryllium with EDS-SDD a test was performed on a pure Be reference material. The spectrum, apart from the $\mathrm{Be}_{K \alpha}$ line $(108.5 \mathrm{eV})$, also contained traces of carbon and oxygen. The latter could stick to the Be target during the sample transfer from the vacuum sealed package to the microscopy chamber via atmosphere, thus leading to surface oxidation. Some contamination by $\mathrm{O}$ upon the sample production cannot be fully excluded. The presence of carbon could be at least partly associated with the electron beam-induced deposition of $\mathrm{C}$-containing species in the microscope chamber. 
2.2.2 Ion Beam Analysis. IBA measurements were performed with particle induced $\mathrm{x}$-ray emission (PIXE), ${ }^{3} \mathrm{He}-$ based Nuclear Reaction Analysis (NRA) and Elastic Backscattering Spectroscopy (EBS) [13] at the Ion Microprobe end-station of the Ruđer Bošković Institute Tandem Accelerator Facility using a $3 \mathrm{MeV}{ }^{3} \mathrm{He}$ ion beam focused to approximately 5-6 $\mu \mathrm{m}$ spot. Details about the Ion Microprobe and a general description of the experimental setup for dust measurements are in [12,14]. Some recently accomplished modifications dealt with the detection system. A segmented Ortec annular detector with an active area of $400 \mathrm{~mm}^{2}$ and the thickness of $300 \mu \mathrm{m}$ was introduced at the backward angle of $165^{\circ}$ to measure elastically backscattered ${ }^{3} \mathrm{He}$ ions [15]. A standard PIXE detector was placed to cover a solid angle of $0.0118 \mathrm{sr}$, as estimated from the measurements on thick targets of $\mathrm{Al}, \mathrm{Ti}, \mathrm{Mo}$ and $\mathrm{W}$. The same samples were used to determine the PIXE and EBS detectors solid angle ratio $\Omega_{\mathrm{EBS}} / \Omega_{\mathrm{PIXE}}=16.7$ with the estimated relative uncertainty of about $10 \%$. To analyse PIXE spectra the software package GUPIXWIN [16, 17] was used. In front of the NRA detector, positioned in the same geometry $\left(\Omega_{\mathrm{NRA}} / \Omega_{\mathrm{PIXE}}=39.2\right)$ as described in [12], a $110 \mu \mathrm{m}$ thick Mylar foil was placed to absorb the low-energy elastically backscattered primary particles and heavy components of nuclear reactions from the target and to reduce pile-up background. All NRA spectra were simulated using SIMNRA program [18,19] using cross-sections available at the IAEA IBANDL data base [20]. For Be analysis following cross-sections have been used: ${ }^{9} \mathrm{Be}\left({ }^{3} \mathrm{He}, \mathrm{p}_{\mathrm{o}}\right){ }^{11} \mathrm{~B}$ and ${ }^{9} \mathrm{Be}\left({ }^{3} \mathrm{He}, \mathrm{p}_{1}\right){ }^{11} \mathrm{~B}$ [21,22], for ${ }^{9} \mathrm{Be}\left({ }^{3} \mathrm{He}\right.$, $\left.\mathrm{p}_{2}\right)^{11} \mathrm{~B}$ and ${ }^{9} \mathrm{Be}\left({ }^{3} \mathrm{He}, \mathrm{p}_{3}\right){ }^{11} \mathrm{~B}[21,23]$, and for ${ }^{9} \mathrm{Be}\left({ }^{3} \mathrm{He}, \mathrm{p}_{\mathrm{i}}\right){ }^{11} \mathrm{~B}$ $(\mathrm{i}=4,6,7)$ [23]. For carbon reaction ${ }^{12} \mathrm{C}\left({ }^{3} \mathrm{He}, \mathrm{p}_{\mathrm{o}}\right){ }^{14} \mathrm{~N}$ the crosssections were taken from [24,25].

The focused ${ }^{3} \mathrm{He}$ ion beam was scanned over selected areas to create 2D PIXE, NRA and EBS intensity maps using our in-house data acquisition software package SPECTOR [26]. Fortunately, all four analysed samples have the same basic structure, i.e. dust particles on the background of a carbon sticky tab. This feature was used to determine relative beam fluences for each recorded $2 \mathrm{D}$ map for which one could find a sub-region free of dust particles. For each elemental map, total PIXE, NRA and EBS intensities from such sub-regions were compared. The corresponding total intensities normalized to the same number of pixels are proportional to the accumulated charge. On one of the 2D maps a relatively large $\mathrm{W}$ particle was found and used to estimate the absolute ion fluences by EBS and PIXE analysis. Using PIXE and EBS simultaneously and knowing $\Omega_{\mathrm{EBS}} / \Omega_{\mathrm{PIXE}}$ solid angle ratio, the absolute accumulated charge for this particular particle and consequently for other analysed regions could be estimated. As a result, the accumulated charge for any region could be assessed and used for the quantification. The recorded NRA, PIXE and
EBS maps were processed by the PyMCA software package $[27,28]$ to obtain 2D RGB (red-green-blue) maps, i.e. distributions of selected elements/isotopes.

\section{Results}

\subsection{Electron Microscopy: general overview of particles}

Figure 1 is a survey of particles sampled from the pot used in cleaning the outer divertor. Individual particles of various shape and size can be distinguished. Micrographs and X-ray spectra in Figures 2-4 show details of individual particles from the outer and inner divertor. Their origin can be discussed based on the image and spectra analyses.

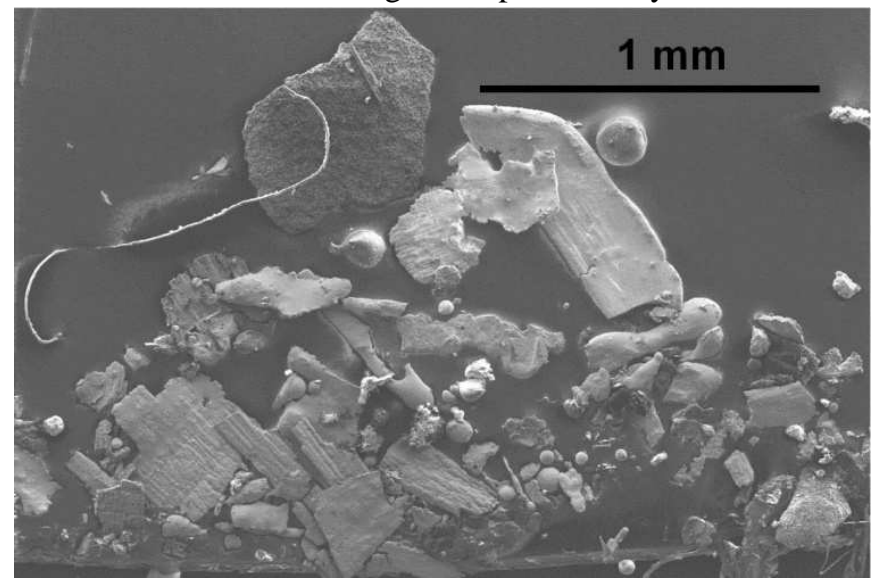

Figure 1. A survey image of the outer divertor particles sampled from the pot.

A small Be droplet (approx. $300 \mu \mathrm{m}$ in diameter) released during limiter melt events (see for instance [29]) in Figure 2 is partly coated by a deposited layer of $\mathrm{W}$ eroded in the divertor. The X-ray spectra recorded under the same conditions (accelerating voltage $10 \mathrm{keV}$, emission 1,6 $\mu \mathrm{A}$, integration time $30 \mathrm{~s}$ ) in Points 1 and 2 differ significantly. While a clear Be feature is recorded in Point 1 , the spectrum from Point 2 shows only heavier constituents in the deposited layer, namely $\mathrm{W}$ accompanied by $\mathrm{C}, \mathrm{N}, \mathrm{O}$ and $\mathrm{Ni}$. It suggests a certain residence time of the droplet in the divertor where it was then coated by W. This also indicates that the droplet landed there not in the last discharges of ILW-3. The detection of $\mathrm{Be}$ in a mixed matter and co-deposits, such as dust from JET, is extremely difficult because of the low Xray energy of $\mathrm{Be} \mathrm{K}_{\alpha}$. As a consequence, even a few nm thick layer of high- $Z$ metal attenuates the Be signal below the detection capabilities of the detector. One also perceives that the $\mathrm{W}$ coating cracks and peels-off exposing the original. The cracked layer and peeled-off particles are indicated by arrows. The same has been noticed on several similar droplets in the analysed matter Be surface. The most probable reason for detachment of the W-rich coating is the internal stress (mechanical or thermo-mechanical 
incompatibility) thus making the layer brittle. However, it is not possible to state with full confidence whether the layer broke already in the tokamak, during the vacuum cleaning or in the last phase of dust preparation for analyses. Taking into account the presence of clean Be surfaces (e.g. point 1 at Figure 2) the latter is the most probable.
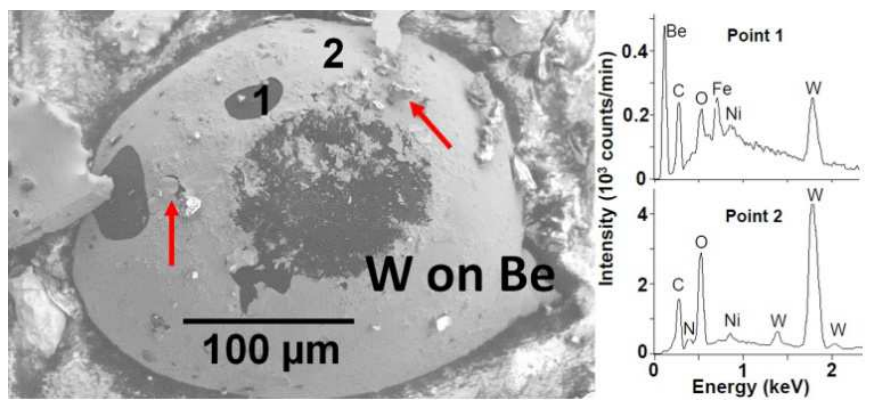

Figure 2. Be droplet coated with a layer of $\mathrm{W}$ eroded from the divertor. X-ray spectra from points 1 and 2 are also presented.

Particles in Figure 3 are different forms of $\mathrm{W}$-based objects. In Figure 3(a) and (b) there are agglomerates composed of tiny flakes detached from the $\mathrm{W}$-coated divertor tiles. The possible mechanism underlying the formation of such mostly empty (ball-like) spheres has been discussed in [9].
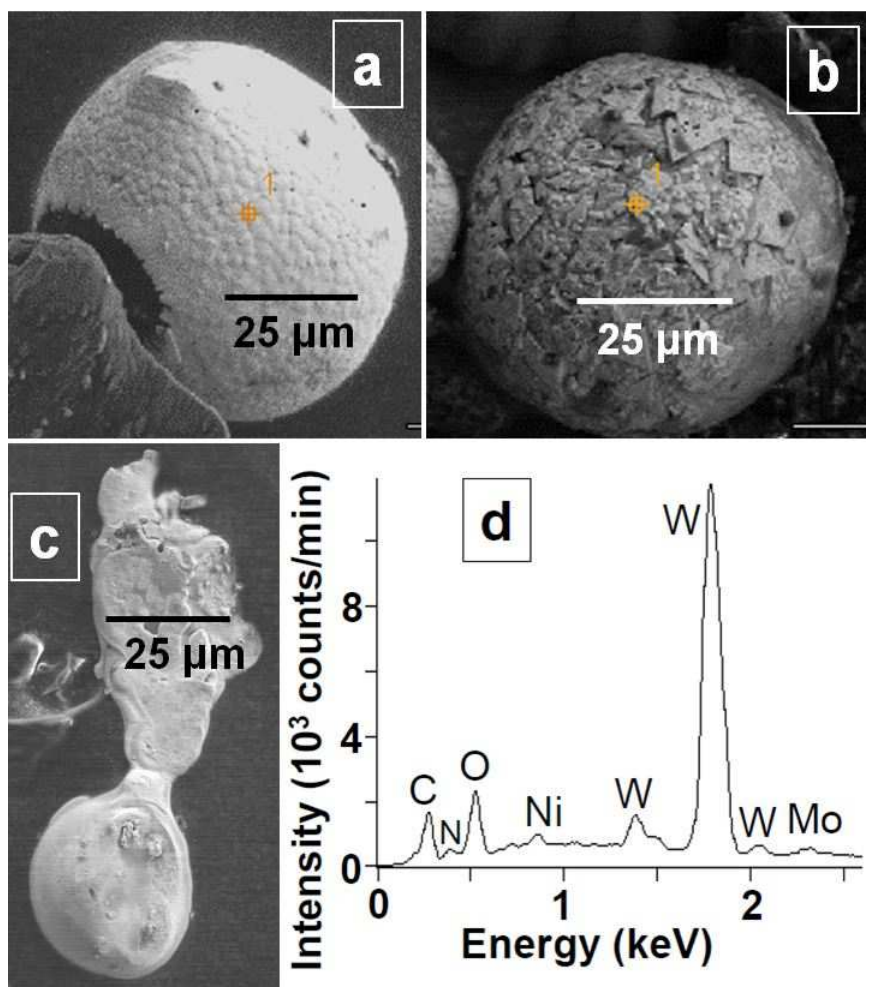

Figure 3. Various forms of W-rich particles: (a) and (b) agglomerates; (c) molten objects and (d) representative X-ray spectrum of particle shown in frame (b).
The object in Figure 3(c) is a re-solidified piece of $\mathrm{W}$ coating. $\mathrm{Ni}$ or rather Inconel droplets shown Figure 4 originate most probably from the melt damage to the grills of antenna for ion cyclotron resonance heating (ICHR).

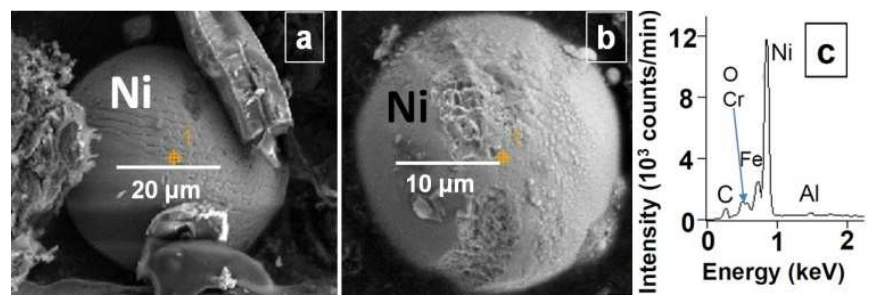

Figure 4. Inconel droplets associated most probably with melt damage to the ICRH grills.

A collection of Be-rich objects from the inner divertor is shown in Figure 5. A droplet in Figure 5(a) contains also a thin C layer as inferred X-ray spectra in Figure 5(b). Other particles are various flakes of peeled-off co-deposits containing a mix of low- $\mathrm{Z}$ and high- $\mathrm{Z}$ elements. Be and $\mathrm{C}$ are the main constituents. The flakes are 100-200 $\mu \mathrm{m}$ big, but it is not possible to conclude whether this was their original size when they detached from the inner divertor tiles. A broken structure in Figure 5(c) provides a clear example of a fragile co-deposit easily disintegrated into smaller fragments.
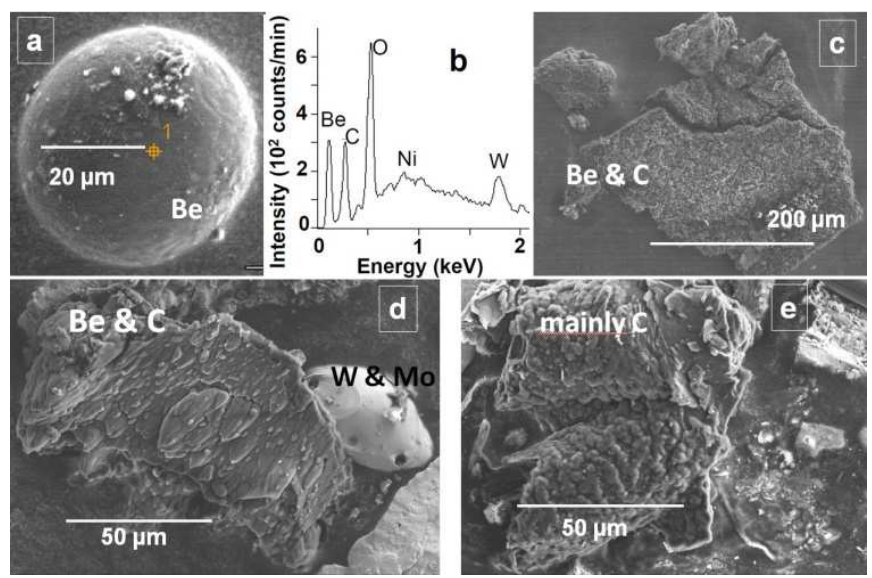

Figure 5. Be droplet (a) and a corresponding X-ray spectrum (b); Be containing co-deposits of various structure: (c) - (e).

Particles isolated from the pots to a Petri dish are fairly large, as demonstrated in Figure 6. These are molten Be pieces, either already partly by co-deposit, Figure 6(a) or pure metal like in Figure 6(b). The object of sharp edges in Figure 6(c) represents a piece broken-off from the Be limiter during in vessel operations by remotely handled (RH) equipment used for in-vessel operation during shut-downs. The origin of the carbon fibre composite (CFC) fragment with $\mathrm{W}$ coating in Figure 6(d) is also most probably linked to the RH operation. 


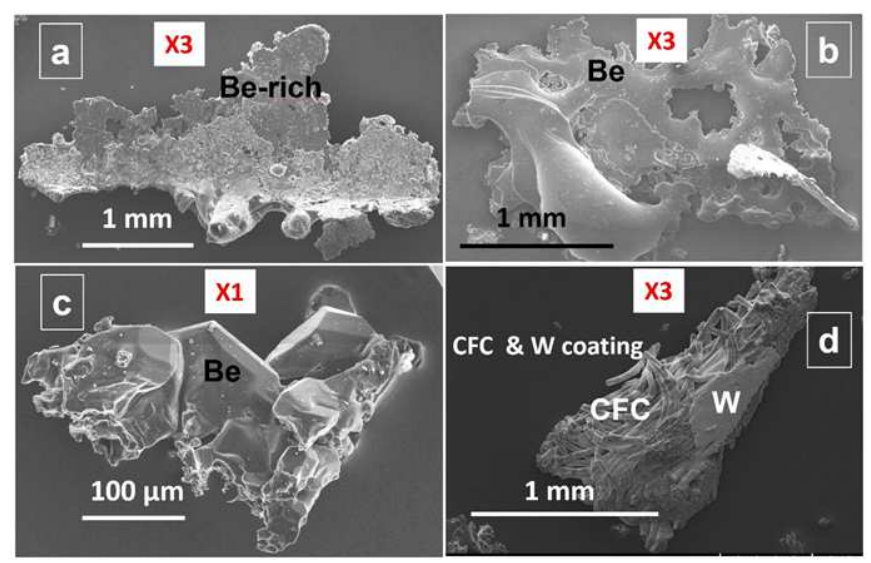

Figure 6. Be and W-CFC particles from the inner (X1) and outer divertor (X3) isolated from the pots to respective Petri dishes.

\subsection{Ion Beam Analysis}

Figure 7 shows PIXE and NRA spectra from the not used (reference) sticky carbon tab. The highest peaks in the PIXE spectrum are from $\mathrm{S}$ and $\mathrm{Na}$, while minor contributions from $\mathrm{P}$ and $\mathrm{K}$ are also present. In the low energy range a clear peak is recorded at the energy corresponding to $\mathrm{O} K \alpha$. However, the escape peak from $\mathrm{S}$ overlaps with $K \alpha$ of oxygen. In this particular spectrum the intensity of the line is large enough to assume the presence of $\mathrm{O}$. In the NRA spectrum there is only a clear $\mathrm{C}$ feature.
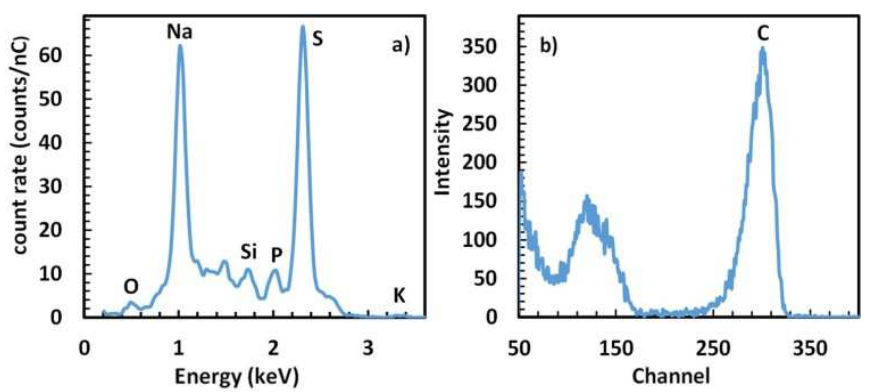

Figure 7. (a) PIXE and (b) NRA spectra of the carbon sticky tab. The spectra were collected with a total accumulated ion charge of $39 \mathrm{nC}$. In case of PIXE, count rate per nC is presented.

\subsubsection{Dust particles collected from the outer divertor.}

The main goal of the IBA measurement was to identify particles containing $\mathrm{D}$ and to associate its presence with other elements. In the following, elemental distributions in the form of 2D maps are presented for several areas on each sample with proven $\mathrm{D}$ presence. The legends provide colourcoded information on the element or isotope and, on the method by which individual species was analysed.

Elemental maps at Figure 8 (a-d) from one of the 8 measured areas on sample 86 (outer divertor, pot interior; see
Table 1) prove that most particles are medium- $\mathrm{Z}(\mathrm{Cr}, \mathrm{Ni}, \mathrm{Fe})$ and high-Z elements with $\mathrm{W}$ being the dominant one.

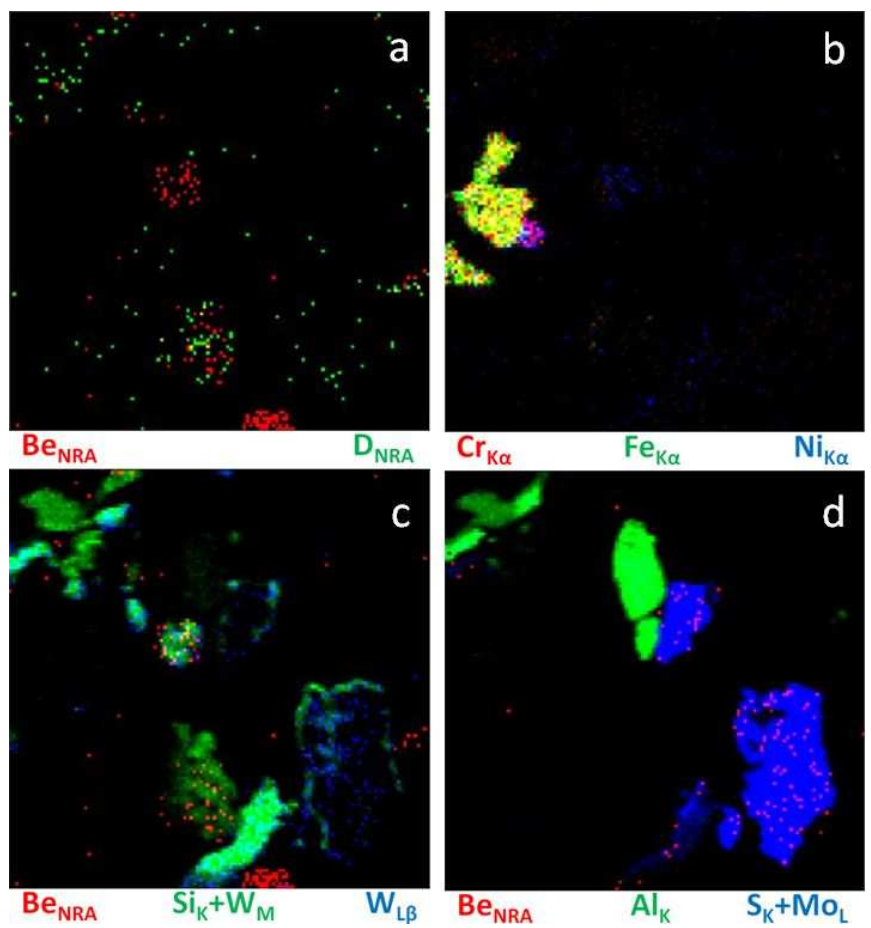

Figure 8. 2D RGB elemental image of sample 86 area with some D detected. Scan size is $880 \times 880 \mu \mathrm{m}$. Image analysis was performed by PyMCA.

In some cases $\mathrm{W}$ is associated with Mo, as inferred from the areal coincidence of the related X-ray signals. Only weak contribution from $\mathrm{Be}$ and $\mathrm{C}$ has been detected. This includes clear identification of three small (approximately 20-50 $\mu \mathrm{m}$ in diameter) particles containing Be. Trace $\mathrm{D}$ features have been found. Their location is not necessarily associated with $\mathrm{Be}$, as can be perceived in Figure 8(a). The overall D yield from this area is about 3.3 counts $/ \mathrm{nC}$ and most of it cannot be associated with any other visible element, except $\mathrm{C}$, where most of the $\mathrm{C}$ detected is the background from the sticky tab. $\mathrm{Si}$ originates most probably from ceramics in some diagnostic tools. Si X-ray line $\left(\mathrm{Si}_{K}\right)$ coincides with the $\mathrm{W}_{M}$ $\mathrm{X}$-ray line. Therefore, in addition to $\mathrm{W}_{M}$ the other line $\left(\mathrm{W}_{L \beta}\right)$ is recorded to properly identify and distinguish both elements. The S K X-ray line $\left(S_{K}\right)$ coincides with $\mathrm{Mo}_{L}$ and those two signals are recorded together. Fortunately, trace quantities of $\mathrm{S}$ in the sticky carbon tape do not disturb the Mo identification in particles with significant Mo content. There are also Al-based particles found all-over the tab but their presence is not associated with the plasma operation; it is a contaminant from the RH equipment; the arm is made of aluminium [30].

For sample X1, containing in general a small number of particles, the measurements were done in six different areas. Most objects are irregularly shaped W particles. Only traces of $\mathrm{D}$ have been detected on a large $\mathrm{Be}(200 \mu \mathrm{m})$ particle in 
the central part of the tab ( $\mathrm{D}$ rate of about 1.7 counts/nC) and at the edge of the nearby large $\mathrm{W}$ and Mo containing particle from the Mo side (D rate of about 1.1 counts/nC).

\subsubsection{Dust particles collected from the inner divertor.}
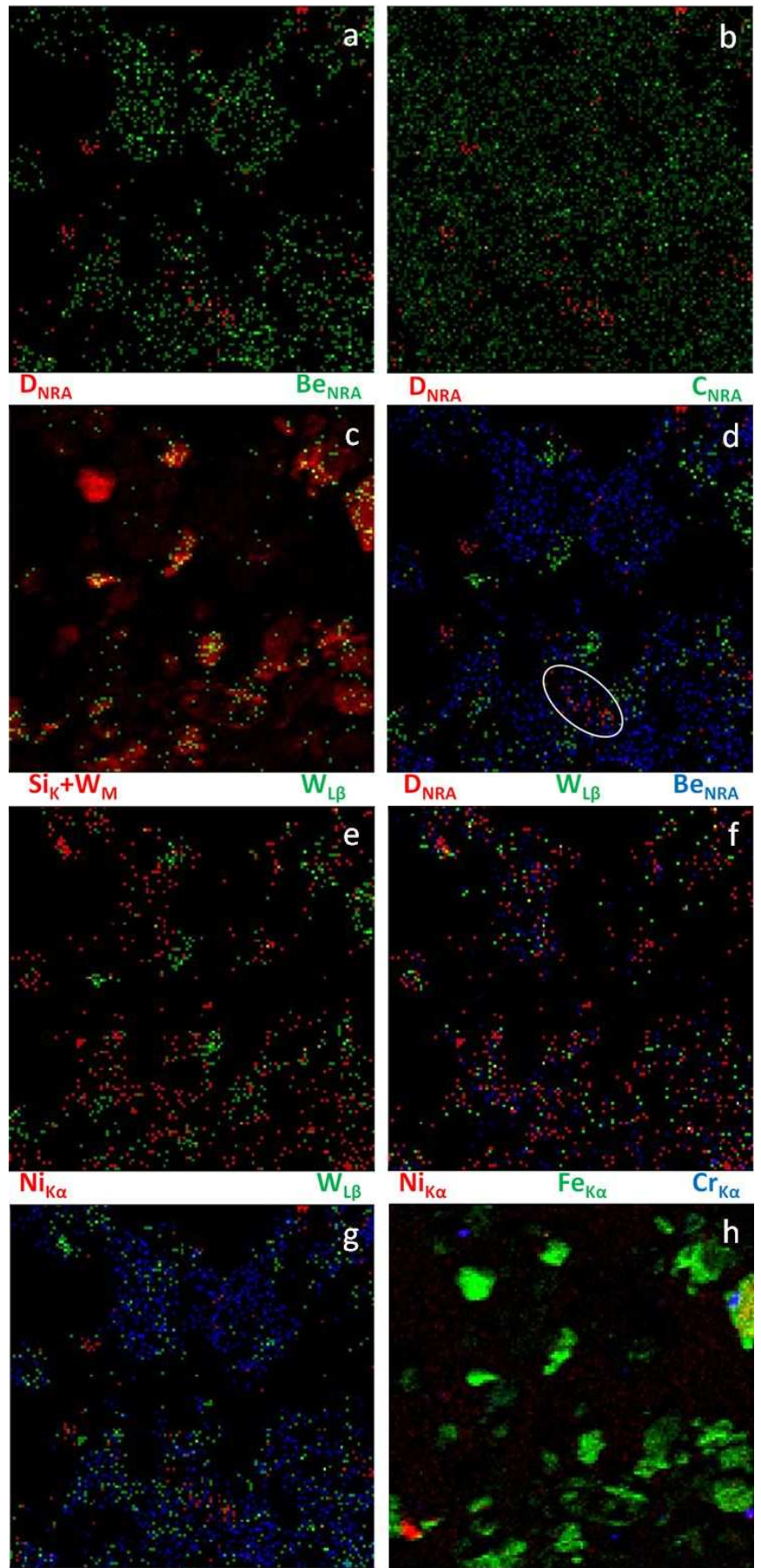

D NRA

\begin{abstract}
$\mathrm{Ni}_{\mathrm{K} \alpha}$
\end{abstract}
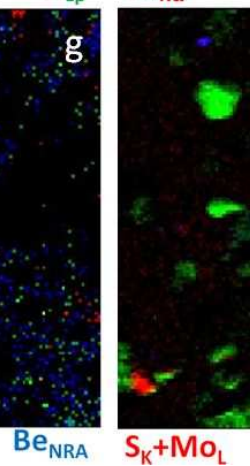

$\mathrm{Fe}_{\mathrm{Ke}}$

$\mathrm{Cr}_{\mathrm{K \alpha}}$

Figure 9. Elemental maps on sample 87, Area 1, rich with a big number of W-based particles with other elements: Ni, Mo, Al, Be and D. Scan size is $800 \times 800 \mu \mathrm{m}$. Table 2 shows estimated concentrations from the area within the white ellipse at the figure $d$.

For sample 87 elemental maps were recorded in ten different areas. Details for three areas (named Area 1, 2 and
3) with distinctly different compositions and detected D are presented. Quantitative data are in Table 2. Maps in Figure 9 (a-h) are from the Area 1 with a number of small W-rich particles, Figure 9 (c-e) and (h). In addition there are a few Al-based objects and a single Mo-dominated particle (h). One may perceive that Be flakes are associated with the presence of $\mathrm{Ni}, \mathrm{Cr}, \mathrm{Fe}$ and, to some extent, with $\mathrm{W}$ located at the flakes' edges. D coincides with $\mathrm{C}$ and only occasionally with $\mathrm{Be}(\mathrm{a}-\mathrm{b})$. It is detected only in some small areas of $40-$ $60 \mu \mathrm{m}$. In this case the concentration ratio of $\mathrm{D}$ to other elements $(\mathrm{Be}, \mathrm{C}, \mathrm{W})$ cannot be determined with a decent level of confidence.
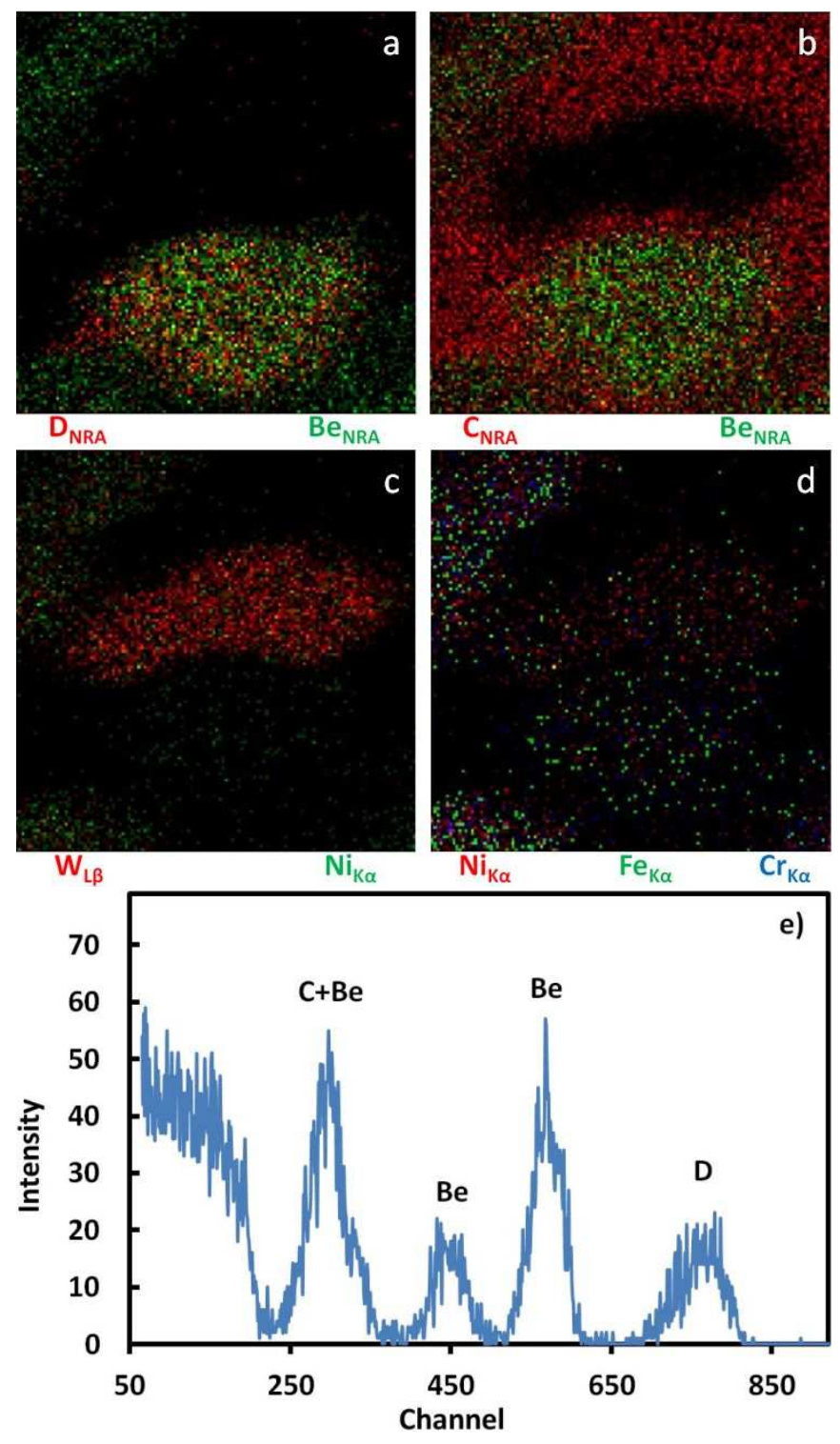

Figure 10. (a-d) Elemental maps on sample 87, Area 2, with three different regions rich respectively with $\mathrm{Be}, \mathrm{W}$ and steel or Inconel components. Scan size is $120 \times 120 \mu \mathrm{m}$; (e) the NRA spectrum related to the selected region with $\mathrm{Be}$ and $\mathrm{D}$ (figure a).

We could perform quantitative concentration estimate only from the small region marked at Figure 9(d) with white 
ellipse, with the results given in Table 2 (Area 1). Further measurement with higher resolution showed rather inhomogeneous distribution of elements within this small region, where $\mathrm{D}$ could be associated with $\mathrm{Be}$ and $\mathrm{C}$. The overall D detection rate from the $800 \times 800 \mu \mathrm{m}$ studied area is about 6.2 counts/nC.

Two clearly separated Be-rich and W-based objects are found in Area 2 shown in Figure 10 (a-d). The comparison of maps in Figure 10 (a) and (c) and quantitative results from Table 2 prove that no $\mathrm{D}$ is traced in the $\mathrm{W}$ rich particle. The presence of D coincides with Be, as seen in Figure 10(a) and (b). From Figure 10(d) one infers the traces of steel or Inconel components: $\mathrm{Fe}, \mathrm{Ni}, \mathrm{Cr}$.
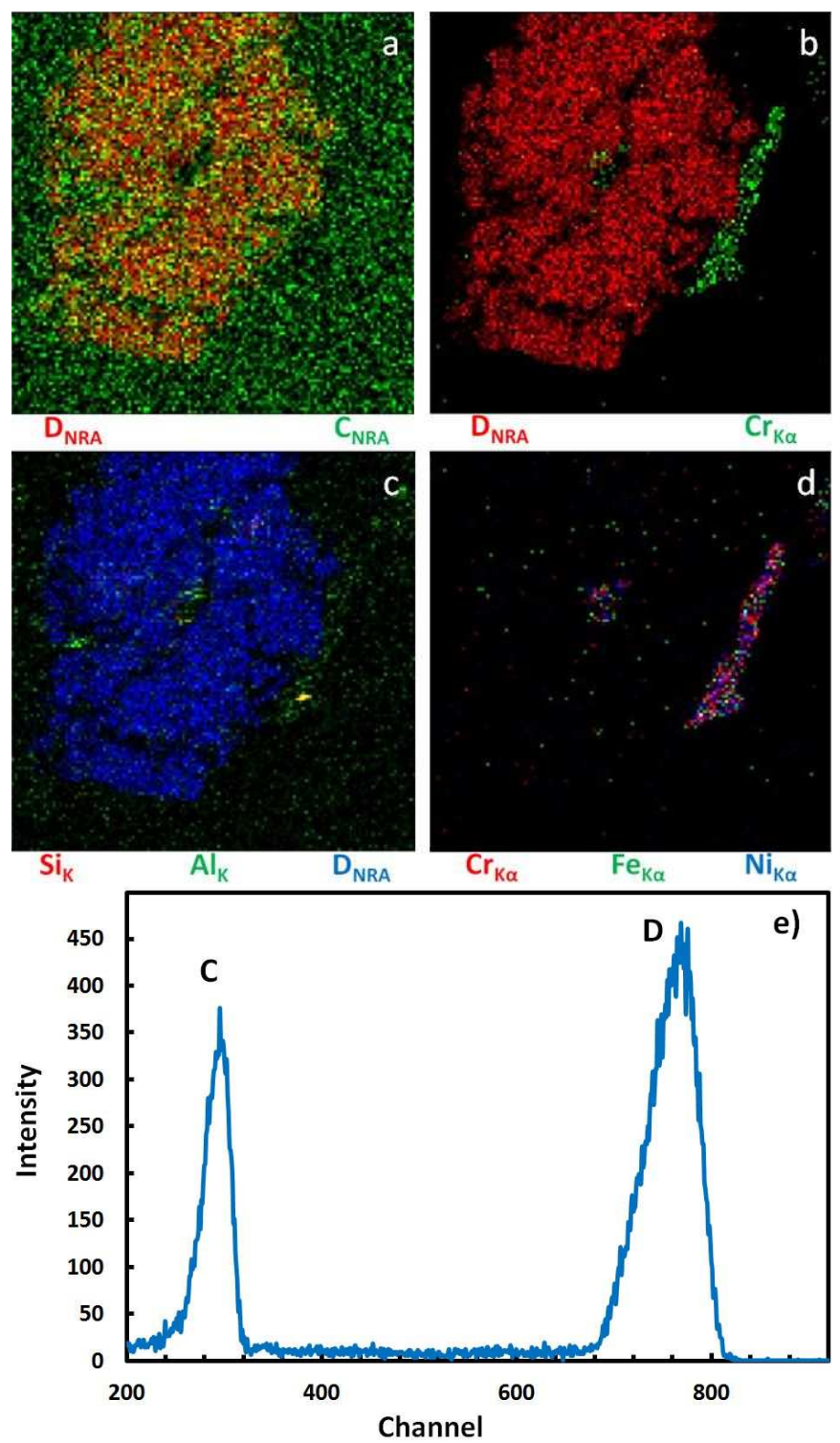

Figure 11. (a-d) Maps for Area 3 on Pad 87 with the highest D content among all studied regions; (e) a related NRA spectrum from the region rich in $\mathrm{D}$.

Figure 11 (a-d) shows distribution of species in Area 3 with a high $\mathrm{D}$ count rate. The overall rate from the whole area is about 400 counts/nC which is about 10 times greater than the sum of all rates from all other areas measured on the four analysed pads. D is detected predominantly (if not only) with a $\mathrm{C}$ particle: C-rich deposit or a debris from the $\mathrm{W}$ coated CFC divertor tile, see details of the divertor construction in $[3,4]$. No $\mathrm{D}$ can be perceived in another particle composed of $\mathrm{Ni}, \mathrm{Cr}$ and $\mathrm{Fe}$. No Be-containing objects have been detected in the entire region, as proven by the NRA spectrum in Figure 11(e).

Table 2. Semi-quantitative elemental atomic concentration estimate for different regions in 2D areas shown at Figures 9-11. Relative uncertainty is estimated at around $20 \%$.

Values for some species are not given if the concentration is below the quantification limit.

\begin{tabular}{|l|l|l|l|l|}
\hline Species & $\begin{array}{c}\text { Area 1 } \\
\text { marked } \\
\text { region } \\
\text { (at \%) }\end{array}$ & $\begin{array}{c}\text { Area 2 } \\
\text { region } \\
\text { with D } \\
\text { (at \%) }\end{array}$ & $\begin{array}{c}\text { Area 2 } \\
\text { region } \\
\text { with W } \\
\text { (at \%) }\end{array}$ & $\begin{array}{c}\text { Area 3 } \\
\text { region } \\
\text { with D } \\
\text { (at \%) }\end{array}$ \\
\hline $\mathrm{D}$ & 1 & 2.1 & & 15.8 \\
\hline $\mathrm{Be}$ & 48 & 60.4 & & \\
\hline $\mathrm{C}$ & 48.9 & 25.9 & $1.3^{\mathrm{a}}$ & 81.9 \\
\hline $\mathrm{O}$ & & 10.3 & & 1.8 \\
\hline $\mathrm{Cr}$ & 0.12 & 0.025 & & 0.01 \\
\hline $\mathrm{Fe}$ & 0.11 & 0.044 & & \\
\hline $\mathrm{Ni}$ & 0.46 & 0.11 & & 0.034 \\
\hline $\mathrm{Mo}$ & 0.23 & & 9.9 & \\
\hline $\mathrm{W}$ & 0.86 & & 90.1 & \\
\hline $\begin{array}{l}\mathrm{Na}, \mathrm{Al}, \mathrm{Si}, \\
\mathrm{S}, \mathrm{Cl}, \mathrm{Ca}\end{array}$ & 0.32 & 1.12 & & 0.46 \\
\hline
\end{tabular}

${ }^{\mathrm{a}} \mathrm{C}$ is the surface layer, thickness given in units $\times 10^{18} \mathrm{at} / \mathrm{cm}^{2}$

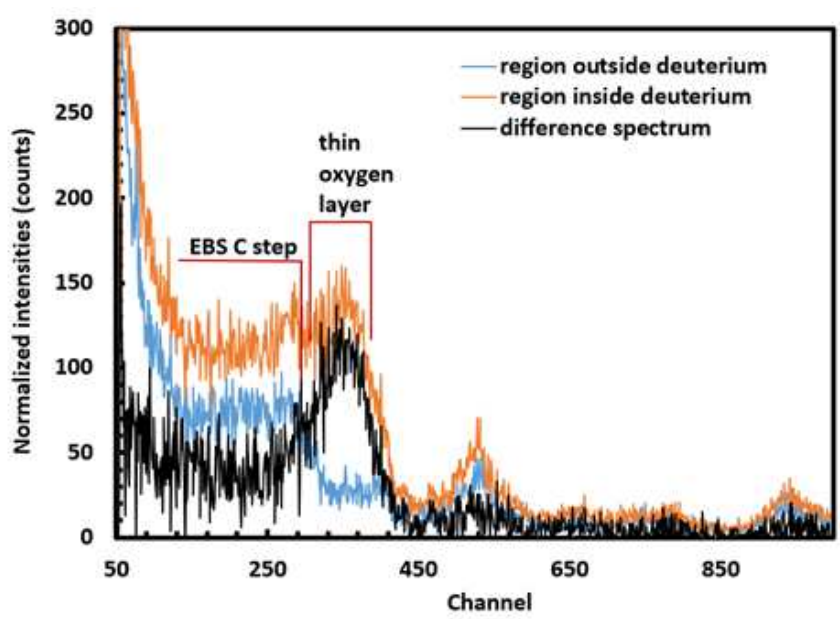

Figure 12. EBS spectra from the area on sample 87, as in Figure 11, for regions with $\mathrm{D}$ and without that isotope. 

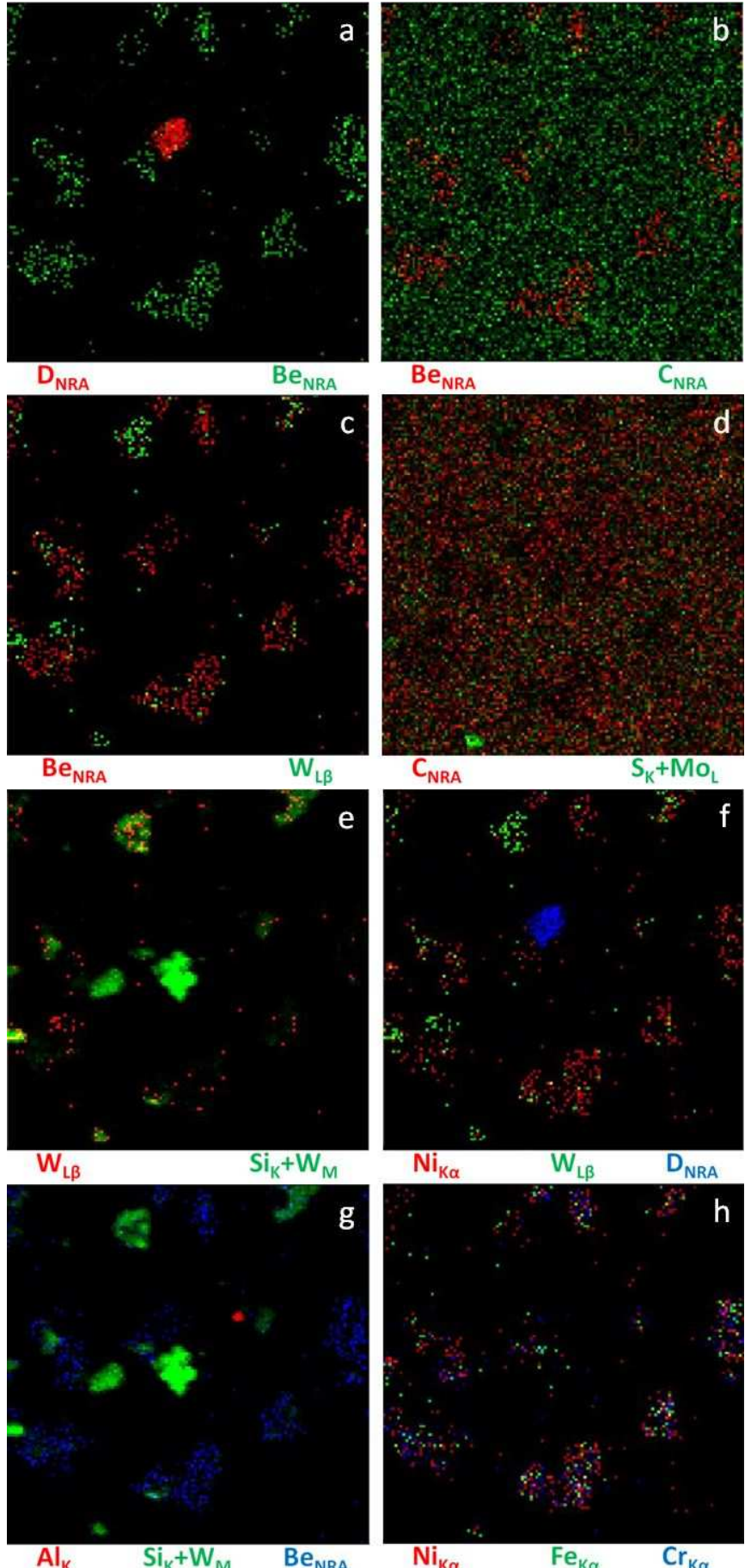

d
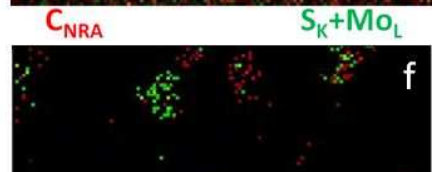

igure 13. Elemental maps from sample $\mathrm{X} 3$

Concentrations of elements and D from the region of Area 3 rich with $\mathrm{D}$ is shown at Table 2 . To summarize, the detected species presented at Table 2 belong to three major categories: (i) D, Be, C, Cr, Fe, Ni, Mo and W are connected with PWI processes in the tokamak plasma operation; (ii) $\mathrm{Na}, \mathrm{Al}, \mathrm{Si}, \mathrm{S}, \mathrm{Cl}, \mathrm{Ca}$ are alien contaminants mostly from the $\mathrm{C}$ sticky tab or introduced to the machine by the RH work [30]. $\mathrm{O}$ is in the third category as a plasma contaminant and species coming from exposure of samples to air.
The amount of $\mathrm{O}$ reported in Table 2 is assessed by GUPIXWIN, but it should be stressed that the peak areas are close to the detection limit and below the limit for quantification. The presence of oxygen in relation to Area 2 is confirmed by the EB spectra in Figure 12 recorded in the D-rich region (orange line) and on the not used sticky carbon tab (blue line). The black line represents the calculated normalized difference spectrum, which clearly shows the presence of a low-Z component a bit heavier than $\mathrm{C}$ in a thin layer. SIMNRA analysis shows that the position fits with the presence of thin layer of surface $O$. The thickness of this layer with $\mathrm{O}$ can be roughly estimated to be not more than $0.4 \mu \mathrm{m}$, assuming the $\mathrm{C}$ matrix.

$\mathrm{D}$ and $\mathrm{C}$ concentrations have been obtained using NRA cross sections for ${ }^{2} \mathrm{H}\left({ }^{3} \mathrm{He}, \mathrm{p}_{\mathrm{o}}\right){ }^{4} \mathrm{He}$ [31] and ${ }^{12} \mathrm{C}\left({ }^{3} \mathrm{He}, \mathrm{p}_{\mathrm{o}}\right){ }^{14} \mathrm{~N}$ [24] nuclear reactions. By far the highest D/C concentration ratio of 0.19 has been obtained for Area $3 \mathrm{D}$ rich region. Using the other set of data for cross-sections [32], one gets related $\mathrm{D} / \mathrm{C}$ concentration ratio of 0.23 .

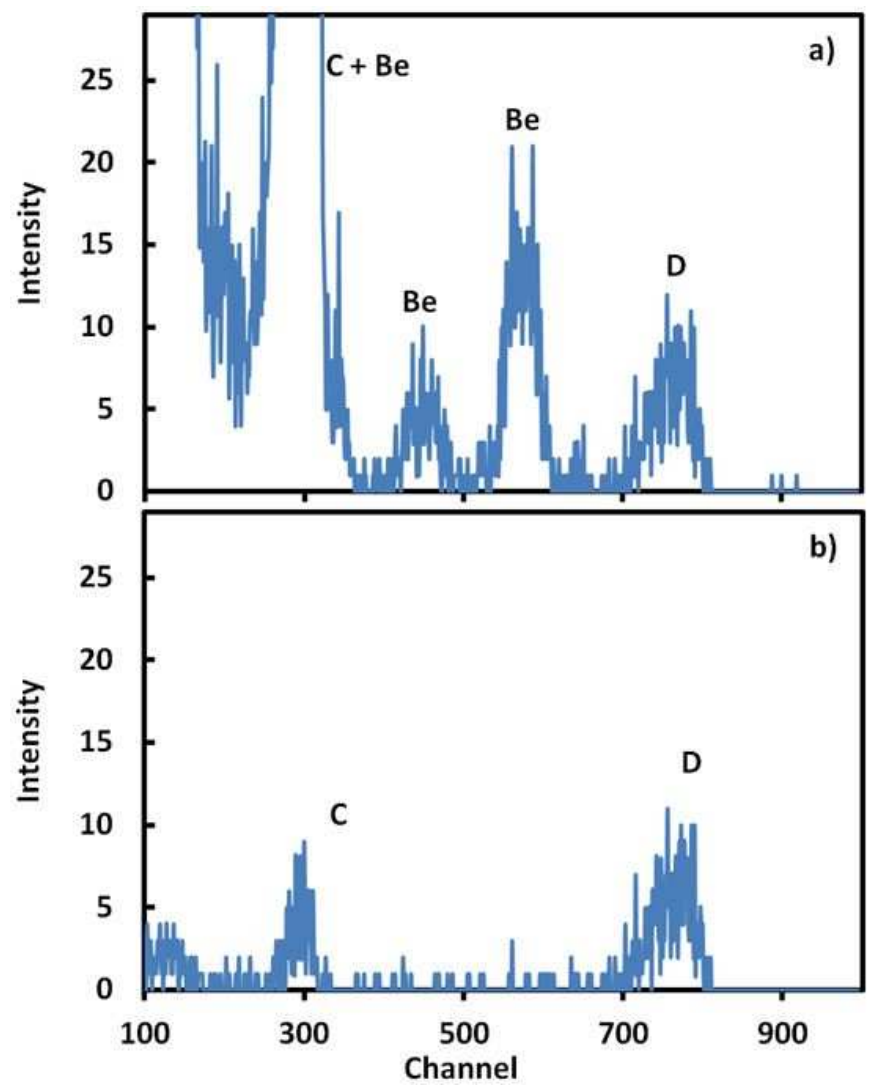

Figure 14. (a) NRA spectrum from the full area of Figure 13; (b) NRA spectrum from the small region with a deuterium-rich particle seen at Figure 13 (a) as a red spot.

On sample X3 (from the Petri dish) seven areas were studied. Figure 13 shows maps of D, Be, W, Si, Ni, Cr, Fe and Al. A number of Be particles is associated with $\mathrm{W}, \mathrm{Cr}$, $\mathrm{Fe}$ and Ni. Only a few $\mathrm{Si}$ and one small Al particle are visible. $\mathrm{D}$ is not associated with any of those particles. One 
may assume, however, that the D signal is associated with a C-based particle of about $100 \mu \mathrm{m}$ in diameter thus corresponding to the spot of the D signal. NRA spectra in Figure 14(a) and (b) recorded respectively from the overall area and from the small region with the D-rich particle visible in Figure 13(a). The latter spectrum is qualitatively similar to that in Figure 11(b), but with a lower count rate for D: 11 counts/nC.

\section{Discussion}

Combination of high-resolution electron microscopy and a set of ${ }^{3} \mathrm{He}$-based micro-IBA enabled imaging, mapping and quantification, from $\mathrm{D}$ to $\mathrm{W}$, in particles contaminated by $\mathrm{Be}$ and also containing tritium in the $\mathrm{MBq}$ range. Specific activities determined by Ashikawa et al. [33] for dust after the ILW-1 campaign were at the level: $6 \mathrm{MBq} / \mathrm{g}$ and 750 $\mathrm{MBq} / \mathrm{g}$ for dust from the outer and inner divertor, respectively. Specific activities for dust after the ILW-3 are still not known but similar values are expected.

The previous work of that kind [12] dealt with co-deposits collected locally from a specific divertor tile, the current one provides the report on loose matter vacuumed from the divertor. The most important outcomes of this work are related to: (i) the identification of respective species and their distribution, (ii) the determination of deuterium content and concentration ratios of $\mathrm{D} / \mathrm{C}, \mathrm{D} / \mathrm{Be}$, and $\mathrm{D} / \mathrm{W}$ in loose particles. The $\mathrm{D}$ content is in general small, not exceeding about 2 atomic \%, except for particles rich with $\mathrm{C}$, where it is noticed that the corresponding $\mathrm{D} / \mathrm{C}$ ratio is distinctly greater than the values for $\mathrm{D} / \mathrm{Be}$ in $\mathrm{Be}$ dominating particles, while $\mathrm{D} / \mathrm{W}$ in $\mathrm{W}$ dominating particles is even lower, and $\mathrm{D}$ rate is close to the practical detection limit values.

While the qualitative aspects of micro-IBA are not questionable, the quantitative side requires an additional comment. As addressed in Section 2.1.1 in connection with discussion of results for Area 3, the assessment of the D/C ratio provides two values: 0.23 and 0.19 dependent on the reaction cross-sections used for spectra analyses. The difference between the two D/C values is about $20 \%$. Based on the discussion in [12] one estimates that the uncertainties of the above reported concentration values are at the level of about $20 \%$ or more. This is because the available NRA crosssections for ${ }^{3} \mathrm{He}$ reactions on $\mathrm{Be}$ and $\mathrm{C}$ are non-validated, and they have been measured only for reaction angles of $150^{\circ}$, $135^{\circ}$ and $90^{\circ}$ (Note: quite recently new cross sections data for Be became available [34]). The quantification of $\mathrm{O}$ is also difficult because validated EB cross-sections for $3 \mathrm{MeV}{ }^{3} \mathrm{He}$ ions are not available. The additional difficulty arises from not homogeneous composition and irregular shapes of the studied objects, as clearly shown in Section 3.1. In the used NRA setup the D presence in $\mathrm{C}$ matrix can be traced to the depth of about $11.4 \mu \mathrm{m}$, while the respective $\mathrm{C}$ and $\mathrm{Be}$ sensitive depths are 8.8 and $8.3 \mu \mathrm{m}$ from related matrices.
The challenges met in studies of non-uniform mixed materials from a fusion reactor do not change the major result of this work: the fuel retention in dust from JET-ILW is associated $\mathrm{C}$, not with metals. This is fully consistent with data for tritium determination in individual dust particles vacuum from JET after the first ILW campaign in 2011-2012 [34]. The combined application of radiography and electron micro-probe analysis has shown the $\mathrm{T}$ content being 100 times greater in carbon particles than in Be or W. The current line of study will be continued on other classes of particles, in particular those deposited on dust monitors.

\section{Concluding remarks}

The contribution of this work to the reactor safety case is the determination of the $\mathrm{D}$ distribution and content in loose matter, especially the relative fuel concentration in individual particles of metals and carbon: $\mathrm{D} / \mathrm{C}$ around 0.2 , while $\mathrm{D} / \mathrm{Be}$ below 0.04 and $\mathrm{D} / \mathrm{W}$ on the level of the detection limit. It clearly shows fuel retention being associated predominantly with C. The result, as discussed in Section 4, is fully consistent with the very low tritium content in metal particles in comparison to the content in C-based particles in dust vacuumed-out from JET-ILW [35]. This proves that the fuel retention in dust is not "averaged" (or mixed) even by the cyclone-type vacuuming. It is associated with concrete types of particles.

These detailed results constitute an additional and needed input to a bigger picture on dust-related issues. Low retention in metal particles, as shown above, together with a very small amount of particles retrieved after each of the three ILW campaigns ( $1 \mathrm{~g}$ per campaign) [5,6,9] and a small fraction Be-rich particles in the loose matter, below $5 \%$ [9] indicate that the operation with metal PFC significantly reduces risks related to dust: generation rate and fuel retention. Only small amount of loose Be dust is found despite melt erosion and splashing of $\mathrm{Be}$ from limiters [29]. As a result, the conversion rate of the eroded material to dust is very low. This is supported by the fact that splashed metal droplets stick firmly to surfaces where they were originally deposited $[29,36]$.

Taking into account differences between JET-ILW and those foreseen in ITER in terms of energy input, discharge time and other operation parameters, it is not intended here to translate the results directly to ITER. However, they allow for a dose of optimism regarding the reactor operation and its availability when the carbon source in the vacuum vessel is limited to intrinsic impurities in materials or loss of vacuum accidents by air ingress. Such statement is justified because results presented above are not isolated findings, but they are coherent with the entire evidence gather in studies of dust from JET-ILW. 


\section{Acknowledgements}

This work has been carried out within the framework of the EUROfusion Consortium and has received funding from the Euratom research and training programme under grant agreement no.633053. The views and opinions expressed here do not necessarily reflect those of the European Commission.

\section{References}

[1] Loarte A et al. 2007 Nucl. Fusion 89 S203

[2] Balden M, Endstrasser N, Humrickhouse P W, Rohde V, Rasinski M, von Toussaint U, Elgeti S, Neu R 2014 Nucl. Fusion 54073010

[3] Matthews G F, Edwards P, Hirai T, Kear M, Lioure A, Lomas P, Loving A, Lungu C, Maier H, Mertens P, Neilson D, Neu R, Pamela J, Philipps V, Piazza G, Riccardo V, Rubel M, Ruset C, Villedieu E, Way M 2007 Phys. Scr. T128 137

[4] Matthews G F, Beurskens M, Brezinsek S, Groth M, Joffrin E, Loving A, Kear M, Mayoral K L, Neu R, Prior P, Riccardo V, Rimini F, Rubel M, Sips G, Villedieu E, de Vries P, Watkins M L 2011 Phys. Scr. T145 014001

[5] Widdowson A, Alves E, Ayres C, Baron-Wiechec A, Brezinsek S, Catarino N, Coad J P, Heinola K, Likonen J, Matthews G F, Mayer M, Rubel M 2014 M. Phys. Scr. T159 014010

[6] Baron-Wiechec A, Fortuna-Zaleśna E, Grzonka J, Rubel M, Widdowson A, Ayres C, Coad J P, Hardie C, Heinola K, Matthews G F 2015 Nucl. Fusion 55113033

[7] Fortuna-Zaleśna E, Grzonka J, Rubel M, Garcia-Carrasco A, Widdowson A, Baron-Wiechec A, Ciupiński L 2017 Nucl. Mater. Energy 12582

[8] Fortuna-Zaleśna E, Grzonka J, Moon S, Rubel M, Petersson P, Widdowson A 2017 Phys. Scr. T170 014038

[9] Rubel M, Widdowson A, Grzonka J, Fortuna-Zalesna E, Sunwoo Moon, Petersson P, Ashikawa N, Asakura N, Hamaguchi D, Hatano Y, Isobe K, Masuzaki S, Kurotaki H, Oya H, Oyaidzu M, Tokitani M 2018 Fusion Engin. Des. 136 579

[10] Coad J P, Rubel M, Likonen J, Bekris N, Brezinsek S, Matthews G F, Mayer M, Widdowson A 2019 Fusion Eng. Des. 13878

[11] Mayer M, Möller S, Rubel M, Widdowson A, Charisopoulos S, Ahlgren T, Alves E, Apostolopoulos G, Barradas N P, Donnelly S, Fazinić S, Heinola K, Kakuee O, Khodja H, Kimura A, Lagoyannis A, Li M, Markelj S, Mudrinic M, Petersson P, Portnykh I, Primetzhofer D, Reichart P, Ridikas D, Silva T, Gonzalez de Vicente S M and Wang Y Q 2020 Nucl. Fusion 60025001

[12] Fazinić S, Tadić T, Vukšić M, Rubel M, Petersson P, FortunaZaleśna E and Widdowson A 2018 Analytical Chemistry 90 5744

[13] Breese M B H, In Handbook of Modern Ion Beam materials Analysis, 2nd ed.; Wang, Y., Nastasi, M., Eds.; Materials Research Society: Warrendale, 2009; 285

[14] Jakšić M, Bogdanović Radović I, Bogovac M, Desnica V, Fazinić S, Karlušić M, Medunić Z, Muto H, Pastuović Ž,
Siketić Z, Skukan N, Tadić T 2007 Nucl. Instrum. Methods Phys. Res. Sect. B 260114

[15] Jeynes C, Colaux J L 2016 Analyst 1415944

[16] Campbell J L, Boyd N I, Grassi N, Bonnick P, Maxwell J A 2010 Nucl. Instrum. Meth. Phys. Res. Sect. B 2683356

[17] Blaauw M, Campbell J L, Fazinić S, Jakšić M, Orlić I, Van Espen P 2002 Nucl. Instrum. Methods Phys. Res. Sect. B 189 113

[18] Mayer M, SIMNRA User's Guide, Report IPP 9/113, MaxPlanck-Institut für Plasmaphysik: Garching, Germany 1997

[19] Rauhala E, Barradas N P, Fazinić S, Mayer M, Szilágyi E, Thompson M 2006 Nucl. Instrum. Methods Phys. Res. Sect. B 244436

[20] Nuclear Data Service, International Atomic Energy Agency (IAEA) Ion Beam Analysis Nuclear Data Library https://www-nds.iaea.org/exfor/ibandl.htm

[21] Barradas N P, Catarino N, Mateus R, Magalhaes S, Alves E, Siketic Z, Radovic I B 2015 Nucl. Instrum. Methods Phys. Res. Sect. B 36421

[22] Wolicki E A, Holmgren H D, Johnston R L, Geer Illsley E 1959 Phys. Rev. 1161585

[23] Lin C S, Hou W S, Wen M 1981Chinese J. Phys. (Taiwan) 19 99

[24] Johnston R L, Holmgren H D, Wolicki E A, Geer Illsley E 1958 Phys. Rev. 1958109884

[25] Moeller S 2017 Nucl. Instrum. Methods Phys. Res. Sect. B 394134

[26] Bogovac M, Bogdanović I, Fazinić S, Jakšić M, Kukec L, Wilhelm W 1994 Nucl. Instrum. Methods Phys. Res. Sect. B 89219

[27] Solé V A, Papillon E, Cotte M, Walter P and Susini J 2007 Spectrochim. Acta B 6263

[28] Software Group, European Synchrotron Radiataion Facility (ESRF), PyMCA X-ray Fluorescence Toolkit Home Page http://pymca.sourceforge.net/

[29] Jepu I, Matthews G F, Widdowson A, Rubel M, FortunaZaleśna E, Zdunek J, Petersson P, Thompson V, Dinca P, Porosnicu C, Coad P, Heinola K, Catarino N, Pompilian O G, Lungu C P 2019 Nucl. Fusion 59086009

[30] Rubel M et al 2020 Phys. Scr. T171 014048

[31] Alimov V Kh, Mayer M., Roth J. 2005 Nucl. Instrum. Methods Phys. Res., Sect. B 234169

[32] Kuan H M, Bonner T W, Risser J R 1964 Nucl. Phys. 51481

[33] Ashikawa N et al 2020 Nucl. Mater. Energy 22100673

[34] Provatas G et al 2020 Nucl. Instrum. Methods Phys. Res. Sect. $B \mathbf{4 7 2} 36$

[35] Otsuka T et al 2018 Nucl. Mater. Energy. 17279

[36] Garcia-Carrasco A et al 2017 Nucl. Mater. Energy 12506 